\title{
Technological Innovation in the Maritime Industry: The Case of Remote Pilotage and Enhanced Navigational Assistance
}

\author{
Ben Brooks ${ }^{1}$, Tim Coltman ${ }^{2}$ and Miles Yang ${ }^{2}$ \\ ${ }^{1}$ (National Centre for Ports and shipping, Australian Maritime College, University of \\ Tasmania, Australia) \\ ${ }^{2}$ (School of Management, Operations and Marketing, University of Wollongong, \\ Australia) \\ (E-mail: Benjamin.Brooks@utas.edu.au)
}

\begin{abstract}
Advances in technological innovation have been deployed to support autonomous or semi-autonomous vehicles in many industries. A question that remains unanswered is why very little progress has been made in remote pilotage over the past 15 years. This paper draws together theories from innovation management and the high reliability organisation literatures to shed light on this question. Using a case study of two Australian ports, we examine a business case for remote pilotage demonstrating that despite positive cost benefit models, ambiguities in benefits exist throughout the ecosystem. The discussion sheds light on unique challenges that port executives face where it is necessary to simultaneously develop a strategy to: (1) manage the internal innovation process, and (2) manage the external consequences of the innovation by mobilising allies, managing opponents, and converting those who are indifferent to the innovation. The main contribution of this paper is to show that any assessment of the innovation challenge facing remote pilotage and enhanced navigational assistance requires the maritime industry to ask new questions not previously considered.
\end{abstract}

\section{KEYWORDS}

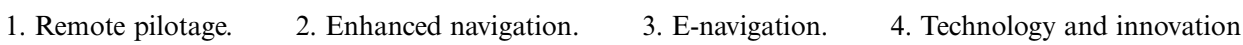
management.

Submitted: 17 December 2014. Accepted: 9 December 2015. First published online: 26 January 2016.

1. INTRODUCTION. Several years ago, in this journal, Hadley (1999) defined Remote Pilotage as "an act of pilotage carried out in a designated area by a pilot licensed for that area from a position other than on board the vessel concerned...". In a follow up global survey of the technologies, issues and usage of technology to support shore-based roles, Hadley (2000) concluded that: 
"The required technology is either available or can be seen as a realistic prospect... However, technology alone will not suffice to make change practicable. The non-technological issues are more intractable but capable of solution. Progress, if realised, can be expected to be slow; the current assessment for the spread of [remote pilotage] is 10-15 years".

Given we are now 15 years post this assessment it would seem useful to revisit the issue and assess the degree of spread that has occurred. A recent European survey of the practice across 23 countries found very little increase in the use of remote pilotage (PWC, 2012). Beyond the maritime industry autonomous or semi-autonomous vehicles are leveraging advances in global positioning technologies and being employed in a wide variety of other industries such as mining (Fiscor, 2012). Robotics and automation are transforming some aspects of surgical practice (Broeders and Ruurda, 2001), driverless trains are common (Valderrama and Jørgensen, 2008). Systems for control of space-based automated systems (e.g., for Mars missions) continue to progress in complexity (Straub, 2014). Each of these environments has faced and continues to face their own unique, complex challenges. The maritime industry is arguably no less unique or complex. However the limited progress around automation (as indicated by Arnsdorf (2014)) is curious, and worthy of further examination, and not just from the context of whether the technology itself is mature enough. Although we highlight some issues associated with the technology itself in the following section, it is not the focus of this paper to examine that particular issue.

The question we pose in this paper is why has the maritime industry been slow to move on remote pilotage? To answer this question we draw insight from the innovation management literature where the management of complex innovations is a key strategic issue (Schumpter, 1950). Much ink has been devoted to the internal and external factors that determine whether promising initiatives will succeed or not (Hayashi, 2013). An internal focus on innovation asserts that familiar drivers of innovation success are leadership, implementation competencies and company culture (Tellis, 2013; Adner, 2012). An external focus requires explicit consideration of the delays and challenges inherent in the innovation environment or ecosystem (Adner, 2012). Far less attention has been given to the management of these internal and external perspectives and the obstacles or barriers that arise in an innovation ecosystem when they are not considered early in the innovation life cycle.

It can be tempting for managers to apply a narrow lens and focus attention on simplifying a complex innovation initiative by concentrating their efforts on getting things right, one operational capability at a time (Coltman et al., 2011; Coltman and Devinney, 2013). For example, anecdotal reports and our own interview work reveal that the first bottleneck managers chose to confront is whether technologies are sufficiently advanced to proceed with the innovation. This approach, however, would seem to be flawed, as technological advances in isolation are rarely sufficient for an innovation to succeed. ${ }^{1}$ In the specific case of remote pilotage, technological advances are nested within an intricate ecosystem of interrelated stakeholders and interdependent resources that include, but are not limited to how pilotage is defined in law; vulnerability of associated technologies (Harati-Mokhtari et al., 2007); a range of operational

\footnotetext{
${ }^{1}$ Innovation is defined in this paper as the process that moves an invention of a new product, process or service forward to successful commercial exploitation (Freeman, 1982)
} 
issues; challenges around insuring ships during remote pilotage; and the cost of associated technologies (e.g., dynamic positioning systems).

This paper does not seek to address all the individual challenges facing remote pilotage as prior work sheds light on some of these issues. For example, Bruno and Lützhöft (2009) examined the issue of remote pilotage and argued that the issue should not be characterised as a technological problem. They assert that a better way to understand the lack of progress is to first consider pilotage as the control of a complex socio-technical system. This led Bruno and Lützhöft (2009) to describe the fundamental problem of remote pilotage as a less effective and inferior means of providing feedback to the pilot. The authors proceed to identify reasonable and relatively inexpensive solutions to mitigate, if not resolve the control problem. However, if solving the control problem is possible, and inexpensive, why have the relevant stakeholders in the maritime industry been slow to move on this issue? Control can only be part of the answer.

In this paper, we argue that the complex challenges facing remote pilotage are unlikely to be solved with a narrow lens that identifies singular innovation challenges. Rather, remote pilotage is an example of an innovation management challenge that requires consideration of the links between multiple parties in the innovation ecosystem. An ecosystem approach requires managers to ask new questions such as: Who sets the rules for how stakeholders in the innovation network will interact? Who hands off to whom in a complex innovation network? What decision rights are retained when components are built by others? Who else needs to use the innovation in order for it to be successful? These questions are increasingly relevant to large and complex innovation initiatives and any failure to consider them can lead to blind spots that hinder the pace of innovation.

We illustrate the innovation management challenges facing remote pilotage with a case study of two Australian port operators. To evaluate the business case for remote pilotage, we consider the shipping movements in two ports and the costbenefit modelling that was performed with respect to implementation of remote pilotage. We argue that an innovation ecosystem perspective provides a more complete assessment of why the maritime industry has been slow to move on remote pilotage.

2. THEORETICAL BACKGROUND. It is well understood that innovation is, by its very nature, a highly unpredictable process. A core reason for this is that any given innovation does not stand alone. Rather, it depends on two areas of focus: internal focus and external focus (Hayashi, 2013). An internal focus asserts that resources and capabilities are important to develop customer insight, building capabilities to execute effectively on the project (Adner, 2012). An external focus suggests that interdependencies in the firm's innovation ecosystem predict innovation success. Interdependencies reflect the contemporary nature of innovation where parts of the innovation are dependent upon other actors or partners to co-create or adopt the innovation (Adner, 2012).

2.1. Internal Execution Focus on Innovation and its Barriers. Expert opinion tends to explain the sources of innovation failure based on two schools of thought: a shortfall in customer insight, and shortcomings in leadership and implementation. This body of research asserts that the key to innovation success lies with evaluating the financial feasibility, identifying the likely benefit to customers, assessing the 
competition, the appropriateness of the supply chain and developing the capabilities to execute the task of building the new product, process or service. For example, Hadjimanolis (1999) used resource-based theory to show that differences in innovation outcomes can be attributed to the differences in resource and capability. Several internal barriers can act on one or more points of the innovation process such as lack of appropriate technical capabilities and HR resources (Hadjimanolis, 1999), excessive perceived risk of innovation (Galia and Legros, 2004), and lack of motivation (Hadjimanolis, 1999).

In a two-decade study in innovation Tellis (2013) concludes that the most important driver of innovation in an organisation is its culture. He argues that "...the cause of failure and success of innovation lies not in hard formulae, models, technologies, buildings or money, but in a soft mushy, difficult-to-grasp, and tough-to-master thing called culture". Innovation culture within an organisation is the best form of insurance an organisation can have in a dynamic environment (Hidalgo and Albors, 2008). Even though nothing is guaranteed, organisations continue to invest in developing an innovation culture to enhance long-term competitiveness.

However, the success rate of innovation is low and managers are all too familiar with the challenges of delivering a project on time and to specification. For example, in a review of 19 peer-reviewed research studies Castellion and Markham (2013) reported new product failure rates of between $30-49 \%$ for the 1945 and 2004 period. This implies that a focus on internal execution and culture may create blind spots that hide critical inter and intra-dependencies that are equally important to innovation success. We discuss these next.

2.2. External Focus on Innovation and its Barriers. Organisations are increasingly recognising that new value propositions are possible when suppliers, business partners and customers work together to co-produce value (Ordanini and Parasuraman, 2011). In other words, innovation frequently takes place within an "innovation ecosystem" and a key distinction between a standard 'competitive strategy' and an 'ecosystem strategy' lies in consideration of actors who lie off the critical path to the end consumer (Adner, 2012). This approach to innovation explicitly accounts for the interdependency risks associated with coordinating complementary innovators (co-innovation risk) and the need to assess the integration risks of having the solution adopted across the value chain (adoption chain risk). Integration or adoption chain risk refers to "the extent to which partners will need to adopt your innovation before end consumers have a chance to assess the full value proposition" (Adner, 2012. p.34) and the assessment of interdependency or co-innovation risks is defined as "the extent to which the successful commercialisation of your innovation depends on the successful commercialisation of other innovations" (Adner, 2012. p.33) as equally important to understand and control.

Studies focusing on innovation ecosystems allow organisations to create value that no single organisation could have created on their own. Not surprisingly, the benefits of these innovation ecosystems - discussed under labels such as open innovation, platform leadership, value networks - have become central to both business strategy and practice. Several studies have also investigated the external barriers to innovation. For example, Madrid-Guijarro et al. (2009) summarise these barriers including insufficient government support (Hadjimanolis, 1999), economic turbulence (Katila and Shane, 2005), lack of market information (Galia and Legros, 2004), lack of information about technologies (Galia and Legros, 2004), lack of external partners possibilities 


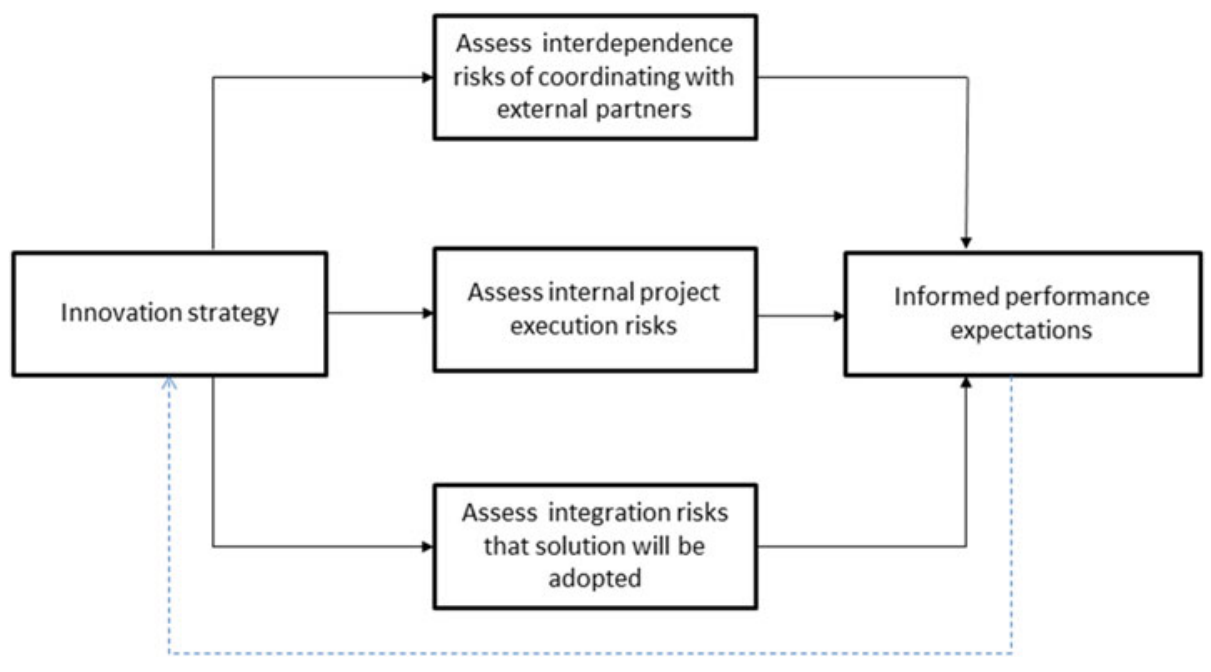

Figure 1. Three Risks of Innovation Ecosystem (adopted from Adner, 2012).

(Mohen and Roller, 2005). These external barriers are related to the focal firm and its partners, which will make the innovation difficult to implement.

Figure 1 provides a graphical illustration of an approach to analysing the risks in an ecosystem. Due diligence requires that once an innovation strategy is developed, organisations consider three risk areas: (1) assess the interdependence risks of coordinating with external partners, (2) assess the internal project execution risks, and (3) assess the integration risks that a solution will be adopted by stakeholders. It is also the case that innovation strategy is likely to be more difficult in complex, highly reliable organisations where multi-layered regulatory barriers can apply. We examine these contextual challenges facing innovation next.

2.3. Innovation in Highly Reliable Organisations. An increasing number of organisations are engaged in innovative products, processes or services in hazardous (in the engineering sense) environments where failure can lead to harmful consequences for the organisation and/or a larger public. Highly Reliable Organisations (HROs) is a term used to denote organisations that devote extraordinary attention to avoiding major errors and dangers because the consequences of failure can be harmful to people, organisations and/or the environment (Bierly, 1995). Typical examples of HROs include nuclear power plants, genetic engineering, air-traffic control, dangerous drugs and the use of pesticides in agriculture. Despite a high number of organisations that might be classified as HROs the literature has not considered the challenges facing innovation in this context. We assert that high operational reliability is at least an aspirational goal in the maritime industry, and a proportion of organisations are likely to meet the criteria for HRO status, including a percentage of ports.

A feature of HROs is that they are complex and tightly coupled. Perrow (2011) asserts that accidents or organisational failures will inevitably result within tightly coupled organisations. Roberts (1990b) argues that HROs use four strategies to increase operational reliability and therefore avoid these failures. These strategies are redundancy, accountability, responsibility and a culture of reliability. Time dependent processes can be responded to with redundancy, making it possible to find errors 
that may otherwise be overlooked. Variance in accountability and responsibility across jobs in HROs can be managed by building in flexibility to counter the negative effects (i.e. holding up aircraft at point of departure when too many are scheduled to land at the same time at the destination). HROs manage singular goal processes by building layers within the organisation (a form of redundancy) that allow changes in the way that the goals are reached (Roberts, 1990a).

La Porte (1996) notes that HROs not only have complex systems with error free expectations, but they often are required to operate continuously at or near peak capacity. Due to this expectation of error free operation, HROs are unlikely to embrace trial and error approaches to innovation where organisations are encouraged to experiment, prototype and 'pivot' as described by Schrage (2000). Bierly et al. (2008) assert that a platform approach to innovation assists during the innovation process in HROs. The platform provides a foundation for organisation-wide business systems that can be used to support modular processes, and to allow managers to understand interdependencies among various core transactions. Platforms enable HROs to stabilise core technology (i.e. nuclear reactors) to maintain reliability.

HROs are therefore not exempt from the innovation challenge. In the sections that follow we begin to address this challenge by investigating technological innovation in a two-site case study of the maritime industry.

3. CASE STUDY. A two-site case study design was used that focuses on understanding the dynamics present within both settings (Eisenhardt, 1989) using an indepth data collection process (Yin, 1994). A triangulation process was used for the case study based on multiple levels of analysis, and multiple data sources such as financial analysis, interviews, focus groups, ship movement data and document analysis. The authors assert that all procedures contributing to this work comply with the ethical standards of the relevant national and institutional committees on human experimentation and with the Helsinki Declaration of 1975, as revised in 2008.

The case study provides a general overview of the ports and their trade characteristics. Second, we report on a financial calculus to identify whether remote pilotage is viable. Finally, this data is discussed in the context of the socio-technical system that moves ships within ports, regulatory advances and also with respect to the innovation literature.

3.1. Port A. Port A is predominantly a bulk-cargo export port. Analysis was performed on vessel movement data between 1 January 2012 and 23 May 2013 for this port. In total, there were 5,956 vessel movements (2,978 visits) recorded, excluding transfers between one berth to another. By trade tonnage, bulk commodities represented $\sim 95 \%$ of trades through the Port. However, bulk carriers only represent $70 \%$ of total movements. This is mostly due to the sheer size and tonnage of the bulk cargo vessels visiting the port. Due to the port characteristics and types of ships being moved, the port typically uses three and sometimes four tugs.

Analysis of vessel Length Overall (LOA) ${ }^{2}$, shows that approximately two-thirds of the movements involved vessels with an LOA greater than $200 \mathrm{~m}$, and $20 \%$ involved vessels with an LOA between 150-200 m. 43\% of the vessels that visited the port

\footnotetext{
${ }^{2}$ Vessel movement data provided do not contain vessel beam.
} 
Table 1. Vessel Visits to Port A.

\begin{tabular}{lccc}
\hline Number of Visits & Number of Vessels & Total Visits by Vessels in this Category & Percentage of Total Visits \\
\hline Single visit & 714 & $714 \cdot 0$ & $24 \%$ \\
$2-5$ visits & 428 & $1,214 \cdot 0$ & $41 \%$ \\
$6-10$ visits & 106 & $754 \cdot 5$ & $25 \%$ \\
$>10$ visits & 18 & $295 \cdot 5$ & $10 \%$ \\
\hline
\end{tabular}

Table 2. Vessel Visits to Port A.

\begin{tabular}{lccc}
\hline Number of Visits & Number of Vessels & Total Visits by Vessels in this Category & $\%$ of Total Visits \\
\hline Single visit & 465 & 465 & $32 \%$ \\
$2-5$ visits & 152 & 760 & $52 \%$ \\
$6-10$ visits & 14 & 140 & $10 \%$ \\
$>10$ visits & 6 & 90 & $6 \%$ \\
\hline
\end{tabular}

accounted for $76 \%$ of the total visits to the port. The percentage of total ship visits is summarised in Table $1.24 \%$ of ships had a single visit and $10 \%$ of ships visited the port more than 10 times. The greatest number of ships (41\%) visited the port 2-5 times per year.

3.2. Port B. Analysis for Port $\mathrm{B}$ was performed on vessel movement data for one calendar year post 2010 . In total, there were 1,001 visits recorded. Data were provided on visit levels, not on movement levels. The percentage of total ship visits is summarised in Table 2.

Analysis of cargo types indicates that the profile of the visiting vessel is distributed across several vessel types. Bulk and general cargo makes up approximately $55 \%$ of the vessels, and 37\% are made up of PCC/PCTC (Pure Car Carrier / Pure Car and Truck Carrier).

Analysis of LOA shows that $55 \%$ of visits involved vessels with an LOA of below $200 \mathrm{~m}$, and another $37 \%$ with an LOA of between $200-250 \mathrm{~m}$. Choosing to target vessels below $150 \mathrm{~m}$ LOA first means that less than $15 \%$ of vessel movements would be covered. However, targeting vessels below $200 \mathrm{~m}$ LOA means that more than three times the number of target vessel movements can be covered.

The analysis in the previous section identifies that $70 \%$ of ships entering Port A are bulk carriers and $21 \%$ are bulk, general cargo and container ships. In Port B, $43 \%$ are bulk carriers and $37 \%$ are car carriers.

4. CASE STUDY ANALYSIS. The analysis was based on an iterative process. First, an assessment of the costs and benefits of remote pilotage was undertaken based on actual pilotage and ship movement data obtained from the case study ports. Second, interviews and publically available data (on issues such as accident costs) were collected to support the analysis.

The benefits in port utilisation are unlikely to be driven by faster movement of vessels, but by improved utilisation of port resources. Project benefits were modelled and quantified around the following:

- Navigational performancelsafety ( $25 \%$ of total benefit). Data indicates that claims for pilot error-related claims made to P\&I Clubs by pilots cost over 
\$1.36 million (adjusted to 2013 Australian dollars) (International Group of P\&I Clubs, 2004) and on average, there is one error for every 15,543 vessel movements in Australia. Significant improvements are likely to have been made in pilot performance since this data was collected, however the cited document is the most comprehensive international analysis available. The aim of implementing a remote system of pilotage would be to use technology to reduce the number of errors to one for every 95,000 vessel movements to be achieved over a 5 year period. This error rate is still well above that experienced in countries such as Germany and Netherlands (International Group of P\&I Clubs, 2004).

- Pilot safety. (10\% of total benefit). Injury costs were modelled based on Australian historical injury data using an annual cost of injury of \$AUD 70,000 (SafeWork Australia, 2012) in 2009 was adjusted for inflation in the model. Injury data for the two ports was reviewed and for Port A we determined that there were 1.40 pilot injuries per 1,000 hours of pilotage; this figure was 1.62 for Port B.

- Pilot utilisation. ( $20 \%$ of total benefit). Removal of pilot transfers will reduce the time needed for pilot transfers, which depend on distance, mode of transfer and other conditions. Benefits in pilot utilisation were modelled by estimating the amount of time saved by removing pilot transfers. Analysis of pilotage duration was performed on vessel movement data between 1 January 2012 and 23 May 2013. (Port A pilotage duration $=77$ minutes; pilotage transfer $=34$ minutes Port B pilotage duration $=70$ minutes, pilotage transfer $=55$ minutes.

- Reduced requirements for pilotage support services such as pilot cutters, helicopter and the associated crew. ( $45 \%$ of total benefit). These were modelled based upon costs in the 2012-13 financial year provided by the port and included payroll costs and overhead, asset maintenance and depreciation.

The benefits reported above do not imply that these are the only contributions from implementing remote pilotage. Bigger ports with busier vessel traffic have the potential to move more vessels under shore-based pilotage, and are expected to reap greater benefits from the innovation. For the two reference ports, project benefits are estimated at between \$3-6 million for the five years modelled, assuming the ability to achieve 900 2,000 vessel movements by Year 5. As a comparison, the numbers of vessel movements at the two reference ports in 2018 are estimated at 6,500 for Port A and 3,000 for Port B.

Total costs of port investment required are not markedly influenced by the volume of vessel traffic in the particular port. For each of the reference ports, the total costs in initial investments and in operating costs for five years was estimated at approximately \$AUS1 $\cdot 8-2 \cdot 0$ million each. This includes both initial investment and annual maintenance costs for the technology during the five years modelled. This model also assumes that the port will not need to install a laser berthing system, or that such a system already exists, because the technology is understood to be critical for certain cargo only, such as liquefied gas, and the decision to install such a system is assumed to be independent of the considerations for shore-based pilotage.

The cost analysis model shows that the bulk $(75 \%)$ of the investment will be incurred in what might be described as a development or 'improvement' stage. This is driven by the fact that the initiatives in the improvement stage will also lay the foundation and infrastructure for shore-based pilotage. The overall financial analysis for the two reference port scenarios is shown in Table 3. 
Table 3. Distribution of Investment Costs (in Australian dollars in 2013).

\begin{tabular}{lll}
\hline & Port A or Similar Ports & Port B or Similar Ports \\
\hline Estimated Net Present Value (5 years) & $\$ 2 \cdot 5$ million & $\$ 0 \cdot 7$ million \\
Estimated Net Cash Flow at Year 5 and Beyond & $\$ 3$ million per year & $\$ 1.5$ million per year \\
Estimated Payback Period & $3 \cdot 3$ years & 4 years \\
Estimated Int. Rate of Return (IRR) & $65 \%$ & $31 \%$ \\
Estimated Return on Investment & $230 \%$ & $88 \%$ \\
\hline
\end{tabular}

Table 4. Break even (zero NPV) analysis.

\begin{tabular}{lll}
\hline Conditions at Break-Even & Port A or similar ports & Port B or similar ports \\
\hline Percentage remote pilotage vessel movement by Year 5 & $4-5 \%$ & $16-17 \%$ \\
Number of remote pilotage vessel movements/year & $\sim 300$ & $\sim 500$ \\
\hline
\end{tabular}

Break-even point (zero NPV) for a particular port is estimated when it achieves 300 500 vessel movements per year under remote pilotage by year $5^{3}$. The actual number of vessel movements required will depend on the actual pilotage cost structure, and the elasticity of costs for pilotage support services, i.e. how quickly can it be adjusted to follow demand. Results of Break-Even (zero NPV) analysis for the two reference port scenarios are shown in Table 4.

This data suggests that remote pilotage is financially viable and that the percentage of vessels that would be required to break-even is typically making 6-10 return visits a year to the ports, If we accept this information and the assumptions that underpin the financial model, this removes a further impediment to remote pilotage. If the financial model breaks-even, and the technology exists why is remote pilotage still absent in a vast majority of pilotage events? Part of the answer may be found by examining the internal and external factors influencing innovation in ports.

5. DISCUSSION. We began this paper by posing the question "Why has the maritime industry been slow to move on remote pilotage?" Our review of the literature indicates that although remote pilotage can be found in places such as the Netherlands and Italy, execution is limited and typically supported by 'older' technologies such as VHF radio and radar (Koester et al., 2007).

The only exception to this limited execution seems to be in Italy, where shore-based pilotage is practised more frequently as an alternative to on board pilotage $(30 \%$ of total pilotage service). The service is provided through VHF radio by a pilot licensed for the port, and is often referred to as VHF pilotage. It is generally applied to ferries that frequently visit the port and to smaller vessels, with the master carrying a special permit to do so. No accidents related to VHF pilotage have been reported in Italy. We summarise the global state of remote pilotage in the Appendix. This does not however

\footnotetext{
${ }^{3}$ Assumes progression of the remote pilotage adoption as follows: half of the Year 5 volume in Year 4, and a third of Year 4 volume in Year 3.

${ }^{4}$ Estimated at $10 \%$ WACC for both ports, which does not include the perpetual value of cash-flow in Year 6 and beyond.
} 


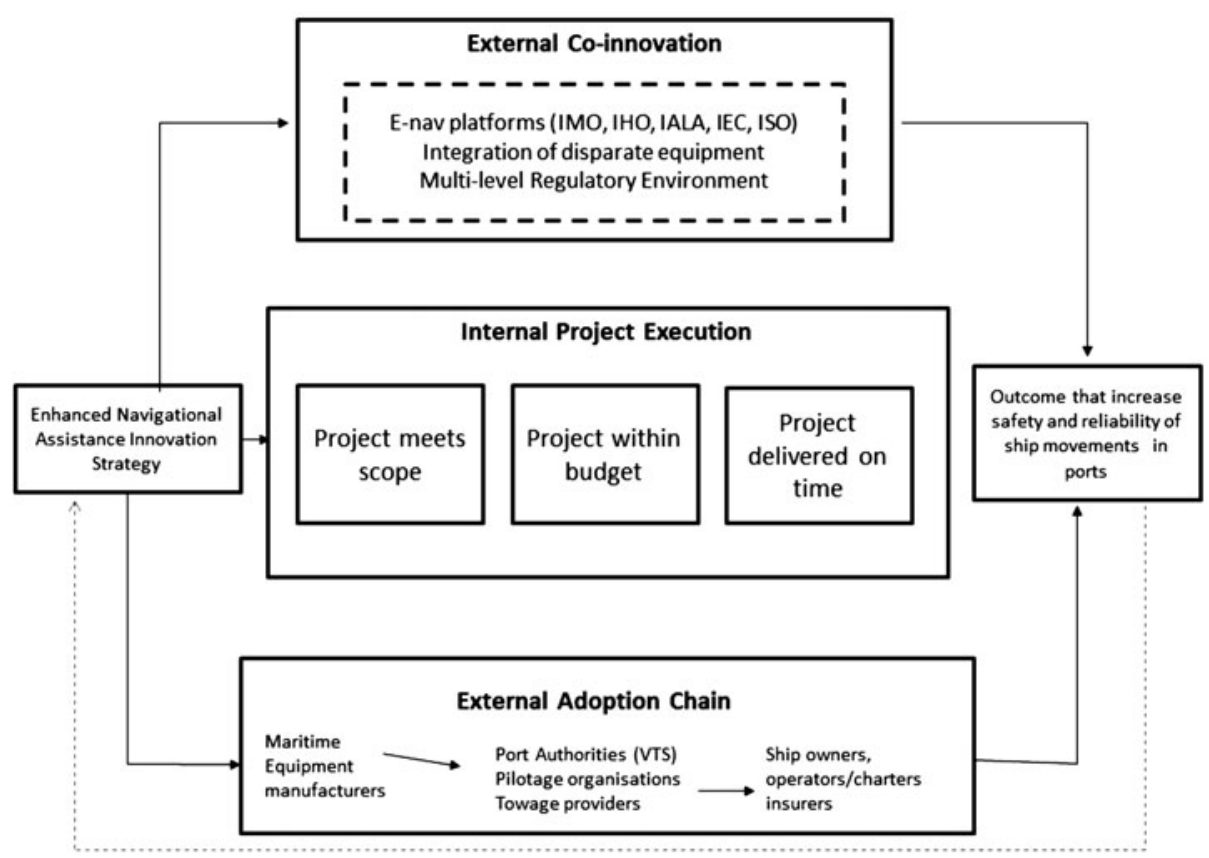

Figure 2. Three Risks of Innovation Ecosystem for Enhanced Navigational Assistance.

lead to the conclusion that this practice is risk-free. Indeed a range of technical/technological issues remain to be solved, including the integrity of positional, navigation and timing systems, COLREG (Collision Regulation) compliance and hacking and jamming immunity/protection. Beyond this are the human factors issues associated with the possible removal of standard cues mariners use to build and maintain situational awareness (such as vibrations of the ship due to engine performance).

The focus on reducing and managing risks and dangers in the maritime industry implies that any innovation will be challenging. This is consistent with the literature on HROs (Bourrier, 2011) where research indicates that HROs mitigate the potential for unexpected consequences and complex technologies through multiple sources of direct and indirect information. However, these are largely internally focussed and can lead to blind spots in the innovation ecosystem, as shown in Figure 2. This Figure directs attention to interdependence risks associated with e-navigation platforms and the integration risks associated with maritime equipment manufacturers, port authorities and ship owners.

As shown in Figure 2, we suggest that an ecosystem perspective should be considered when facing the innovation challenges. Remote pilotage is a typical example of such an innovation management challenge. A narrow lens would not be able to solve the challenge as we discussed in two case studies, rather it requires the consideration of the links between multiple roles in the innovation ecosystem. We argue that managers with an ecosystem perspective will ask different questions to have a more correct assessment of innovation challenges such as: "Who else needs to use the innovation in order for it to be successful?" instead of asking: "How does my company make the innovation successful?" Different questions are increasingly relevant to large and 
complex innovation initiatives. Not asking those new questions can lead to the innovation failure or at least hinder the pace of innovation. We discuss the ecosystem perspective in detail next.

5.1. Assessing the Interdependence with Complementary Innovators. One major role in supporting innovation is that of complementary innovators. In order to understand current progress around remote pilotage and enhanced navigational assistance, the discussion needs to include external interdependencies. International development in the area of maritime regulation provides a platform for discussing co-innovation work. The most obvious of these developments is the International Maritime Organization (IMO)-led e-navigation initiative.

E-navigation has been defined as "The harmonized collection, integration, exchange, presentation and analysis of marine information on board and ashore by electronic means to enhance berth-to-berth navigation and related services for safety and security at sea and protection of the marine environment." (IMO, 2014a) The "e' therefore is not simply electronic but refers to "the overall conceptual, functional and technical architecture" that includes "process description, data structures, information systems, communications technology and regulations" (IMO, 2014b).

The IMO initiative on e-navigation is an important co-innovation for Enhanced Navigational Assistance for two key reasons:

- The e-navigation initiative provides a platform based on the overarching e-navigation architecture that includes standard-based innovations (i.e., Common Maritime Data Structure, the Maritime Service Portfolios and the International Hydrographic Office's S-100 standard).

- The e-navigation initiative directs attention towards addressing several important deficiencies in the current maritime systems that would support enhanced navigational assistance (i.e., Improved, harmonized and user-friendly bridge design, standardised reporting, improved Vessel Traffic Service communication), (IMO, 2014a). This includes addressing deficiencies in equipment design "A clear need has been identified for the application of good ergonomic principles in a wellstructured human-machine interface as part of the e-navigation strategy" (IMO, 2014a. p.2). This also led to the development of the (currently draft) guidelines on the development of e-navigation systems associated with Software Quality, and Human Centred Design (HCD) (see IMO, 2013).

Regulatory efforts such as the e-navigation initiative are but one piece of the ecosystem approach to innovation. Successful innovation also requires an understanding of the external adoption chain, and in order to address this we need to 'widen the lens' through which we view the related technologies.

5.2. Assessing Integration Risks in the Adoption Chain. The case study illustrates the importance of the wider ecosystem when considering innovation such as remote pilotage or Enhanced Navigation Assistance-related technology. In the case of the movement of ships within a port environment the list of stakeholders includes: port authorities, vessel traffic services, pilotage organisations, towage providers and independent companies or technology providers. In the case of the authority, it might be privatised, quasi-privatised or publically owned.

For any innovation it is important to ask a very simple question for each stakeholder in the adoption chain - what is the value of the innovation when transition costs are 
Table 5. The External Adoption Chain for Remote Pilotage Technologies.

\begin{tabular}{|c|c|c|}
\hline Ecosystem partner & Description of Value in the Ecosystem & Outcome \\
\hline $\begin{array}{l}\text { Maritime equipment } \\
\text { manufacturers }\end{array}$ & $\begin{array}{l}\text { Manufacturers must see an opportunity to sell } \\
\text { enough units that the development is profit- } \\
\text { able. This has previously linked to carriage } \\
\text { requirements, however no carriage require- } \\
\text { ments for new 'ENA' systems. }\end{array}$ & Ambiguous (?) \\
\hline Port Authorities: & $\begin{array}{l}\text { Remote pilotage may improve outcomes by } \\
\text { being able to move bigger ships more safely, } \\
\text { move ships in more extreme environmental } \\
\text { conditions and may also create efficiencies in } \\
\text { current ship movements. This may lead to a } \\
\text { range of benefits and lower costs. The value is } \\
\text { a clear positive, as long as safety is maintained/ } \\
\text { improved. }\end{array}$ & Positive $(+)$ \\
\hline $\begin{array}{l}\text { Pilotage } \\
\text { Organisations: }\end{array}$ & $\begin{array}{l}\text { Remote pilotage removes pilots from the } \\
\text { workplace they enjoy, reducing fees, and re- } \\
\text { quiring significant change in function }(-) \text {. It } \\
\text { could be positive if it leads to improvements in } \\
\text { safety (?) External pilotage providers are paid } \\
\text { by the ship movement so increased berth util- } \\
\text { isation would lead to more movements (+). } \\
\text { New technology might need to be procured } \\
\text { and integrated (-). }\end{array}$ & $\begin{array}{l}\text { Ambiguous (?) tending either } \\
\text { direction depending on one's } \\
\text { perspective. }\end{array}$ \\
\hline Towage providers & $\begin{array}{l}\text { If ENA included technology for tugs this would } \\
\text { be a cost to the towage company ( }- \text {, however } \\
\text { they are likely to be in a similar position to } \\
\text { pilotage organisations, and revenue would only } \\
\text { increase with increased ship movements }(+) \text {. }\end{array}$ & Ambiguous (?) \\
\hline $\begin{array}{l}\text { Vessel Traffic } \\
\text { Services: }\end{array}$ & $\begin{array}{l}\text { Remote pilotage may require VTS Officers to } \\
\text { improve their skills to support ENA-related } \\
\text { technologies, and many ports do not currently } \\
\text { provide a service that is consistent with being a } \\
\text { VTS. The associated costs could be significant } \\
\text { (-). Improvements in the ability to monitor } \\
\text { safe movement of vessels by VTS is difficult to } \\
\text { quantify (?) }\end{array}$ & Ambiguous (?) \\
\hline $\begin{array}{l}\text { Ship Owners and } \\
\text { Operators }\end{array}$ & $\begin{array}{l}\text { Who pays for the pilotage/tug service depends } \\
\text { on whether ship is time chartered or not (?) } \\
\text { Remote pilotage is unlikely to reduce these } \\
\text { costs }(-) \text {, however it may speed up arrivals/ } \\
\text { departures (+). }\end{array}$ & Ambiguous (?) \\
\hline
\end{tabular}

considered? Do they stand to gain or lose from the innovation? Table 5 applies this approach for Remote Pilotage technologies, identifying whether the value is positive $(+)$ ambiguous (?) or negative (-). Our analysis suggests that there is still a large degree of ambiguity in the value proposition. This is not unresolvable, but would require a detailed and potentially port specific evaluation in order to confirm the value proposition along the adoption chain.

5.3. Case Study and Paper Limitations. The case study as represented suffers from several limitations that are worth highlighting. First, the two case study ports are not 'representative' of all ports around the world. Ports have different mixes of 
'trades' and these are associated with different ship types. The two ports used in this case study do not, for example, currently attract cruise ships. It would not be appropriate to compare the risks of remotely piloting a bulk carrier with the remote piloting of a cruise ship with 7000 people on board. Having said this, the cruise ship is likely to have vastly superior navigational and manoeuvring technologies, more highly trained crews, and a larger number of officers. One could infer from this argument that cruise ships are more 'technically appropriate' candidates for remote pilotage.

Despite the appeal of cost-analysis and net present value calculations in industry there are limitations associated with these calculations. Specifically, the calculations rest on an assumption that there is a single future (when many different scenarios emerge in any innovation lifecycle) and while this approach is considered the standard for business cases, they typically underestimate the true costs of technological innovation. In fact work by Flyvbjerg et al. (2009) demonstrates that this 'base-rate neglect' occurs regularly in large infrastructure projects; that are typically 'over budget, or time, over and over again'. Port operators might benefit from further research that assesses the extent to which previous technological innovations (e.g., Dynamic Under-Keel Clearance, Port Management or Vessel Arrival systems) have met cost, time and scope predictions.

We note that the case study asserted that $80 \%$ of the benefits are associated with improvements in navigational safety, pilot safety and pilot utilisation and pilotage support services. We also acknowledge that the assertion is based on operational data and interviews from a limited sample of ports, and may not be generalizable to other ports. The derived results suffer from the general limitations of case study interviews including recall bias, the representativeness and generalizability of the selected population, and the accuracy of self-reported information, and estimations of improvements in navigational safety that cannot yet be tested. To be fair, however, all benefit modelling is limited by factors such as these, and no benefit modelling exists without an associated set of assumptions.

It is possible that technology might bypass remote pilotage altogether and leap to completely unmanned ships. Current research in this area still presumes that a pilot would embark the vessel: "The ships will be manned while departing and entering port and unmanned during ocean-passage" Porathe et al. (2014. p.1). Further, we acknowledge that a range of technological, legal and operational issues place a 'drag' on the implementation of remote pilotage. A ready, off-the-shelf remote pilotage system is not currently on the market and from this perspective it could be argued that the technology is yet to fully mature. Covering all possible operational issues is beyond the scope of this paper and we direct readers to Hadley $(1999 ; 2000)$ and to Bruno and Lützhöft (2009), where more detailed explanation of these issues is given.

5.4. Precautionary Innovation. The case study has explored remote pilotage as an example of an innovation where outcomes are uncertain and the consequences of innovation are potentially harmful and unacceptable. We have considered this as a challenge of innovation in Highly Reliable Organisations (HROs).

In such an environment, deep engagement within the 'ecosystem' is necessary. We refer to this type of innovation as 'precautionary innovation'. It differs from traditional forms of innovation because in HROs the primary innovation strategy is one that must take a precautionary approach to deal with hazards and risk.

In these contexts, traditional decision making approaches that rely on cost, benefit and discount rate calculations to build a business case for innovation can break down because the consequences of failure often generate quite different world views among 
the decision makers involved in the innovation ecosystem. This leads to a lack of consensus on what parameters should be used to support a rational decision making calculus. It also generates concerns regarding the extent to which cost and benefit numbers can be believed, undermining any approach to support an evidence-based approach to innovation decision making.

In the case of remote pilotage a wider innovation management lens is required because it is often not possible to separate internal innovation from the external consequences of the innovation on society and the environment. The case of remote pilotage illustrates an example of precautionary innovation and the pace of technological innovation will be dependent upon clear design rules that can be used to guide component development. This is an important contribution to the maritime literature, to the current debate around e-navigation, and innovation management literature more broadly. Little is known about the decision processes that underpin such innovation where managers are required to simultaneously manage both (1) the process from idea to development and ultimately to commercialisation, and (2) the potential consequences of the innovation on the wider ecosystem.

The two port case study builds upon work by others on the issue of remote pilotage (Hadley, 2000; Bruno and Lützhöft, 2009). Hadley (2000) identified the range of technical and non-technical issues that would need to be addressed. Bruno and Lützhöft (2009) demonstrated that any technology that aims to implement remote pilotage must be able to resolve the challenge of providing effective and superior feedback to the pilot when ashore. This paper adds further dimensions to this debate. It has shown that while cost-benefit modelling might demonstrate positive results, an innovation that seeks to resolve the various technological, legal, operational and insurance issues will need to do so from an 'ecosystems perspective'. In other words, the innovation management challenge has as much to do with technology as it does with the way proponents of remote pilotage mobilise co-innovators, manage opponents in the adoption of change, and convert those who are indifferent to the innovation. Because these efforts occur within organisations that cannot accept system failure we have identified the need for 'precautionary innovation', pointing to the tension between the risk seeking of innovation and the risk avoidance (management) that goes with high reliability. We have posed the question: Why has the maritime industry been slow to move on remote pilotage? Our contribution in this paper has been to frame this debate in a broader management context and to recognise that the success of any innovation in commercial navigational technology should ask new questions about the way stakeholders in the innovation ecosystem interact, to maximise the likelihood of success.

\section{ACKNOWLEDGMENTS}

This research has been supported by a grant from the Australian Research Council (LP 120100422) and Ports Australia. The views expressed here are solely those of the authors who are listed in alphabetical order.

\section{REFERENCES}

Adner, R. (2012). The Wide Lens. Portfolio/Penguin.

Arnsdorf, I. (2014). Rolls-Royce Drone Ships Challenge \$375 Billion Industry: Freight. http://www.bloomberg.com/news/articles/2014-02-25/rolls-royce-drone-ships-challenge-375-billion-industry-freight. Accessed 17th August, 2015. 
Bierly, P. (1995). Culture and High Reliability Organisations: The Case of the Nuclear Submarine, Journal of Management, 21(4), 639-656.

Bierly, P. E., Gallagher, S., and Spender, J. C. (2008). Innovation and Learning in High-Reliability Organisations: A case study of United States and Russian nuclear attack submarines, 1970-2000. IEEE Transactions on Engineering Management, 55(3), 393-408.

Bourrier, M. (2011). The Legacy of the High Reliability Organisation Project, Journal of Contingencies and Crisis Management, 19(1), 9-13.

Broeders, I., and Ruurda, J. (2001). Robotics Revolutionizing Surgery: The Intuitive Surgical "Da Vinci" System. Industrial Robot: An International Journal, 28(5), 387-392.

Bruno, K. and Lützhöft, M. (2009). Shore-Based Pilotage: Pilot or Autopilot? Piloting as a Control Problem. Journal of Navigation, 62(3), 427-37.

Castellion, G., and Markham, SK. (2013). Perspective: New Product Failure Rates: Influence of Argumentum ad Populum and Self-Interest. Journal of Product Innovation Management, 30(5), 976-979.

Coltman, T. and Devinney., T.M., (2013). Modeling the Operational Capabilities for Customized and Commoditized Services. Journal of Operations Management, 31(7/8), 555-566.

Coltman, T., Devinney, T.M. and Midgley, D.F. (2011). Customer Relationship Management and Firm Performance. Journal of Information Technology, 25(3), 205-219

Eisenhardt, K. (1989). Building Theories from Case Study Research. The Academy of Management Review, 14(4), 532-550.

Fiscor, S. (2012). Sandvik to Supply Largest Underground Mine Automation System. Engineering \& Mining Journal, 213(11), 124-126.

Flyvbjerg, B., Garbuio, M., and Lovallo, D. (2009). Delusion and Deception in Large Infrastructure Projects: Two models for Explaining and Preventing Executive Disaster. Californian Management Review, 51(2), 170-193.

Freeman, C. (1982). The Economics of Industrial Innovation. The MIT Press.

Galia, F. and Legros, D. (2004). Complementarities between Obstacles to Innovation: Evidence from France. Research Policy, 33(8), 1185-1199.

Hadjimanolis, A. (1999). Barriers to Innovation for SMEs in a Small Less Developed Country (Cyprus). Technovation, 19(9), 561-570.

Hadley, M. (1999). Issues in Remote Pilotage. Journal of Navigation, 52(1), 1-10.

Hadley, M. (2000). Remote Pilotage and Enhanced Navigation Assistance. PhD thesis, Nottingham Trent University.

Hatari-Mokhtari, A., Wall, A., Brooks, P., and Wang, J. (2007) Automatic Identification System (AIS): Data Reliability and Human Error Implications. Journal of Navigation, 60(3), 373-389.

Hayashi, AM. (2013). The Inside and Outside View of Innovation. MIT Sloan Management Review, 4(3), 39-42.

Hidalgo, A. and Albors, J. (2008). Innovation Management Techniques and Tools: A Review from Theory and Practice. $R \& D$ Management, 38(2), 113-127.

IMO. (2013). International Maritime Organization. Proposed Draft Guidelines on Human Centred Design. NAV59/6.Annex 4.

IMO. (2014a). International Maritime Organization. Development of an e-Navigation Strategy Implementation Plan: Report of the Correspondence Group on e-navigation. NCSR 1/9.

IMO. (2014b). International Maritime Organization. Development of an e-Navigation Strategy Implementation Plan. Background information related to the Development of e-Navigation. NCSR 1/ INF.5.

International Group of P\&I Clubs (2004). Pilotage Sub-committee Report on Pilot Error Related Claims Over US\$100,000 from 20.02.99 to 20.02.04. http://www.simsl.com/PilotError.pdf Accessed 26th August 2015.

Katila, R. and Shane, S. (2005). When Does Lack of Resources Make New Firms Innovative? Academy of Management Journal, 48(5), 814-829.

Koester, T., Anderson, M. and Steenberg, C. (2007). Decision Support for Navigation. FORCE Technology, Draft Report DMI 107-27358.

La Porte, T. (1996). High Reliability Organisations: Unlikely, Demanding and at Risk.' Journal of Contingencies \& Crisis Management, 4(2), 60-71.

Madrid-Guijarro, A., Garcia, D., and Van Auken., H. (2009). Barriers to Innovation among Spanish Manufacturing SMEs. Journal of Small Business Management, 47(4), 465-488.

Mohnen, P. and Roller, L. H. (2005). Complementarities in innovation policy. European Economic Review, 49(6), 1431-1450 
Ordanini, A., and Parasuraman, A. (2011). Service Innovation Viewed through a Service-Dominant Logic Lens: A Conceptual Framework and Empirical Analysis. Journal of Service Research, 14(1), 3-23.

Perrow, C. (2011). Fukushima and the Inevitability of Accidents. Bulletin of the Atomic Scientists, 67(6), 44-52.

Porathe, T., Prison, J., and Man, Y. (2014). Situation Awareness In Remote Control Centres For Unmanned Ships. Human Factors in Ship Design \& Operation Conference, London, UK.

PWC. (2012). Study of Pilotage Exemption Certificates. http://ec.europa.eu/transport/modes/maritime/ studies/doc/2012-09-18-pec.pdf. Accessed on 25th September 2014,

Roberts, K. (1990b). Some Characteristics of One Type of High Reliability Organisation, Organisation Science, 1(2), 160-176.

Roberts, K. H. (1990a). Managing High Reliability Organisations. California Management Review, 32(4), 101-114.

SafeWork Australia (2012). The Cost of Work-Related Injury and Illness for Australian Employers, Workers and the Community: 2008-09. http://www.safeworkaustralia.gov.au/sites/swa/about/publications/pages/ cost-injury-illness-2008-09. Accessed 26th August 2015.

Schrage, M. D. (2000). Serious Play: How the World's Best Companies Simulate to Innovate. Harvard Business School Press.

Schumpeter, JA., (1950) Capitalism, Socialism, and Democracy. New York: Harper.

Straub, J. (2014). Command of a Multi-Tier Robotic Network with Local Decision-Making Capabilities. International Journal of Space Science and Engineering, 2(3), 225-247.

Tellis, G. (2013). Unrelenting Innovation: How to Create a Culture for Market Dominance. Jossey-Bass.

Valderrama, A. and Jørgensen, U. (2008). Urban Transport Systems in Bogot and Copenhagen: An Approach from STS. Built Environment, 34(2), 200-217.

Yin, R.K. (1994). Case Study Research. Sage. 


\footnotetext{
${ }^{5}$ Source: team consultation with contacts in the Faculty of Maritime Studies, Jade University
} Italy

Nature of Shore-

Based Pilotage

Bring a vessel to a loca-

Bring a vessel to a location

\section{Criteria and}

Consideration

Provider inside the port where it is

safer for a pilot to board

About $5 \%$ of total pilotage mission (2011)

Applies to Incoming

vessels only

Incoming and outgoing

Consider size and cargo

that can participate

LOA and draft

quency of past visits

the master

pilots

Performed by licensed pilots

From VTS centre

Performed by licensed pilot

From VTS centre

ing on-board pilots (or

masters holding PEC)

\section{location}

assistance:

fification on the additiona

service

Remote pilotage:

limit on size and draft

From traffic/radar centre

$\mathrm{VHF}$

VHF pilotage as an alternative to on-

board pilotage

In good weather only

$30 \%$ of all pilotage

missions

Applies to ferries and

small vessels

Generally outgoing

vessels, but may

apply to incoming

Frequency of visits

Favourable weather

Performed by licensed

pilots

Not necessarily from

VTS centre
Norway

No shore-based pilotage in

place

In bad weather, pilot may

guide vessel from pilot boat to a place where pilots can board safely 